\title{
Imaginarios juveniles y participación política de jóvenes universitarios de la ciudad de Lima en el proceso electoral $2016^{1}$
}

\author{
Jerjes Loayza Javier \\ Universidad Nacional Mayor de San Marcos, Lima, Perú \\ mxerxeslj@gmail.com
}

\begin{abstract}
RESUMEN
Las elecciones presidenciales y congresales celebradas en el año 2016 fueron el punto de partida para la aplicación de entrevistas semi estructuradas que profundizan en el significado de la política para la población juvenil en la ciudad de Lima. A través de las reflexiones discursivas juveniles universitarias vertidas, se describen planteamientos sobre la política que refieren su necesaria reconstrucción. La juventud universitaria consultada posee una activa participación en el cambio de sus propias instituciones universitarias, por lo cual visualizan una política distinta y renovada. En síntesis, se concluye un planteamiento deseoso de migrar hacia nuevas resignificaciones de la política en el Perú.
\end{abstract}

Palabras Clave: política, juventud, corrupción, apatía

\section{Ideals and political participation of the young university students in Lima, in the election process in 2016}

\begin{abstract}
The elections held in 2016 to designate both the new president and the respective congressmen were the starting point for the application of semi-structured interviews that deepened the meaning of politics by the youth population in Lima. Through the university youth discourse reflections known at the time, the statements about politics and its necessary restoration have been detailed. The consulted university youth has an active participation around the institutional change of their respective university representatives, so they visualize a different and renewed policy. In summary, it is concluded that this is an avid approach to migrate towards new ways of redesigning politics in Peru.
\end{abstract}

KeYwords: Politics, youth, corruption, apathy

1 Dedicado a Perla, quien acompañó atenta la proyección, sistematización y redacción del texto. 


\section{Introducción}

La política representa una importante construcción socio teórica que implica la solución de problemas sociales y colectivos. Su caracterización en América Latina se ha vuelto una profesión en manos de hombres y mujeres que, en la inserción partidaria, busca detentar el poder para cambiar y transformar su correspondiente país en beneficio del interés colectivo. Sin embargo, en el Perú la población no se ha sentido representada, siendo negativa la crítica hacia los presidentes, Congreso de la República y a toda autoridad representativa. En buena cuenta ello se debería a los escándalos de corrupción que se han producido en los últimos años. En este contexto, las elecciones representarán un mercado de regateos en donde cada candidato busca atraer carismáticamente los votos, en lugar de ofrecer una propuesta cuerda, posible y clara.

En el contexto de las elecciones presidenciales es en donde se pueden explorar emociones y sensibilidades en torno a la política dado que se estará rodeado del marketing político, de las promesas partidarias, de los esfuerzos caudillistas y de todo lo que significa la maquinaria masiva del bombardeo electoral y lo que representa detentar el poder durante cinco ańos. En medio de esta batalla de propuestas personalistas y expectativas colectivas, la población define hacia quiénes derivar su confianza y su voto. En este grupo encontramos a las juventudes que en el intervalo entre los 15 y 29 años representan en la ciudad de Lima, al año 2015, al 27,1\% de la población total de la ciudad, es decir 2409385 jóvenes (Senaju, 2015). Sin embargo en las elecciones municipales 2015-2018 postularon un total de 3462 jóvenes, de quienes se eligieron apenas a 182 de ellos (Senaju, 2015). Esta contradicción provocará que la política sea un espacio de poder dirigido, en su mayoría, por una gerontocracia que desconfiará de las juventudes para dirigir el país monopolizando todo espacio político. Sin embargo, la juventud, como importante bono demográfico, debería ser vislumbrada como referente de emprendedurismo y de innovación tecnológica, siendo clave para todo Estado.

La investigación formulada se basa en los discursos en torno a la política de la juventud propositiva interesada en cambios y transformaciones sociales. A partir de entrevistas basadas en la experiencia política de sus actores, se entreteje una sistematización e interpretación que busca refrescar la dinámica teórica en torno a la política, rebasando toda postura racional y enrumbándonos hacia una sociología política del cuerpo y las emociones (Loayza, 2013a). Tal como lo establece Dussel (2006) las instituciones políticas están agotadas atravesando un proceso entrópico y fetichizado dada la auto referencia de la que sufre. Este es el rol de la sociología política, criticar los presupuestos teóricos a partir de las cotidianidades ciudadanas que retan toda alusión teórica de corte europeo, racional e institucional.

Es así que nos preguntamos lo que sucede con la política institucionalizada amparada en el poder estatal representativo y en sus instituciones más importantes. Se 
analiza cómo adecúan y utilizan las categorías políticas las juventudes entre 18 y 25 años de edad de la ciudad de Lima, en la coyuntura de las elecciones presidenciales del año 2016. Se ahonda en lo que sienten cuando perciben el término "política», así como en las críticas y recomendaciones en torno a esta. Se busca rastrear los prejuicios, opiniones, miedos y conjeturas que se entretejieron en dichas elecciones presidenciales. Además, se reconocen estrategias políticas para afrontar problemas de diversas modalidades en sus organizaciones de origen.

La investigación que se presenta a continuación tiene como método a la teoría fundamentada, en donde el trabajo de campo permite la construcción de los indicadores teóricos y la perfección de los instrumento de recolección de datos. Asimismo se aplica el método fenomenológico profundizando las motivaciones, fantasías y sueños de cada entrevistado y entrevistada. Se aplicaron entrevistas semi estructuradas a 15 mujeres y 11 hombres de distintos distritos. En dicha muestra se incluyó a juventudes pertenecientes a organizaciones estudiantiles de universidades públicas y privadas de la ciudad de Lima. Los jóvenes estudiantes pertenecen a las siguientes instituciones: Universidad Nacional Mayor de San Marcos, Universidad Nacional de Ingeniería, la Universidad Nacional Federico Villarreal y la Escuela Nacional de Arte Dramático, Pontificia Universidad Católica del Perú, la Universidad Ricardo Palma y la Universidad Las Américas. Las entrevistas se realizaron en el intervalo comprendido entre febrero y junio del año 2016, en plena coyuntura de las elecciones presidenciales, puesto que dicho entorno será propicio para concatenar el interés generalizado (gracias al marketing político, a los debates y a toda la maquinaria electoral que tiene lugar cada 5 ańos en todo el país) y las categorías políticas más resaltantes como democracia, representatividad y participación.

\section{Antecedentes}

Un importante hecho que conmovió al planeta fue el de los Indignados que tuvo lugar en España entre los años 2011 y 2012. Gracias a este fenómeno se analizan las nuevas formas en que los movimientos sociales, en manos de jóvenes manifestantes, vienen desfilando más allá de las fronteras y de los aspectos culturales: las emociones colectivas forman un cuerpo de sentimientos aunados por la crítica a los gobiernos. La juventud frente a la corrupción y al dogma habría reaccionado tomando la forma de independencia y, gracias a los académicos, de reformistas (Biagini, 2012). Esta "toma de conciencia», se derivaría de la decadencia del sistema político español en el cual la población no se sentía representada, en tanto todo Estado moderno supone ser resultado de la voluntad de cada ciudadano que desea interactuar en una sociedad pacíficamente, dentro de una lógica predecible que deviene de la propia historia (Adrianzén, 2010). Como establece Lechner (2002: 38) «la ciudadanía sí será capaz de movilizarse cuando el estado de cosas existente se vuelva insoportable». 
Una herramienta muy innovadora que ha sido utilizada ha sido la edición digital denominada photoshop que se utilizó para promocionar candidatos, ideologías y el estatus buscado por personas a través de la técnica (Roitman, 2012), con lo cual se rebasan los límites de los partidos políticos tradicionales. La recurrencia de los indignados ha sido mundial aunque con especificidades en cada país y localidad, con una energía colectiva avasalladora sin precedentes en todos los casos contando con indignados «en cualquier parte del mundo, así en Finlandia como en Noruega, en Italia o en Espańa» (Klein, 2012, p. 90). De esta manera las juventudes buscan un protagonismo cada vez mayor, acercándose sincréticamente al ámbito público y el ámbito privado, superando las dicotomías y polaridades (Agudelo-Ramírez, Murillo-Saá, Echeverry-Restrepo, PatińoLópez, 2010). Para Castells (2009) se fomentan cada vez más espacios de realidad virtual de sociabilidad, todo al punto de que «comunicar es compartir significados mediante el intercambio de información y la transformación del entorno de las comunicaciones afecta directamente a la forma en que se construye el significado y, por tanto, a la producción de las relaciones de poder» (Castells, 2012, pp. 23-24).

El caso peruano fue muy bien analizado por Enrique Fernández (2015) que nos señala el modo en que las organizaciones juveniles en el año 2014 lograron menguar sus diferencias políticas e inclusive personales, sumando las fuerzas de grupos tradicionales e innovadores. Su vínculo con el movimiento de los «indignados» estuvo basado en las estrategias utilizadas, tales como el uso de las redes sociales: «mientras se cocinaba la aprobación de la Ley, coordinaron entre los núcleos sindicales y colectivos políticos que organizaron las primeras acciones de protesta, logrando captar la atención de otros actores no sindicales» (Fernández, 2015, p.126). Las tecnologías de la información y comunicación propiciarán transformaciones no solo al momento de compartir sus sentires, sino de construir el propio discurso. En el otro extremo no participativo, investigué a jóvenes no organizados en el contexto de las elecciones presidenciales del año 2011, profundizando en sus discursos, proponiendo que la apatía que reflejan sus testimonios no son, en absoluto, sinónimo de rehuir de la política misma, sino de crítica hacia esta (Loayza, 2013b).

Para referirnos a las motivaciones juveniles, apuntaremos hacia sus subjetividades colectivas, las cuales se entenderán como «todas las acciones, enunciaciones, discursos de reconfiguración y autoafirmación de la idea de sí mismo, especie de anclaje identificatorio que se evidencian en expresiones, construyendo el sentido de la vida» (López, 2011, p.17). Es importante identificar «en las prácticas discursivas (aparentemente banales, cotidianas, superficiales) elementos explicativos que permiten dar cuenta de la importancia de la subjetividad en términos del andamiaje de lo público» (González, 2012, p. 155). Por ello es que se decide partir de una noción del poder menos exclusiva y más propicia a la cotidianidad y a las intersubjetividades. 
En este contexto de incesantes cambios, Aguilera (2012), al momento de explicar el comportamiento de los estudiantes de secundaria que se movilizaron en Chile, nos permite comprender el choque entre enfoques antiguos de pensar la política desde el Estado centrado en demandas, es decir en un repertorio "antiguo", mientras que las juventudes chilenas se «apuntaban a un conjunto de preocupaciones de orden «relacional» entre autoridades y estudiantes, respondiendo a un repertorio «nuevo» o emergente» (Aguilera, 2012, p. 104). Este desfase es palpable en países como Chile en donde el padrón electoral ha envejecido dando lugar a una auto marginación juvenil: «las razones que han motivado esta conducta se fundamentan en un descontento con la política y con los actores que la ejercen» (Araya-Castillo y Etchebarne, 2014, p. 238).

De esta forma en América Latina las juventudes «aspiran a crear normas y leyes que les permitan salir de las condiciones de miseria y atraso sin dejar su cultura y su forma de organización: aspiran a ser tomados en cuenta como iguales entre diferentes» (Piñeyro, 2013, p. 48). Podemos concluir, entonces, la necesidad repensar la formación de los/as jóvenes, a partir de la nueva cultura juvenil que se está gestando y en diálogo con el contexto en el que están inmersos. Es necesario hacerlo teniendo en cuenta a cada uno en su originalidad, su historia personal y social, «reconociendo la posibilidad que tienen de asumirse como personas dueñas de su libertad, capaces de comprometerse con el mundo en que viven» (Carena, Pisano y Tessio, 2009: 31).

\section{Concepciones juveniles acerca de la política}

Para conocer el modo en que la política cobra significados diversos que no necesariamente van en relación directa con sus conceptos clásicos modernizantes propios de una concepción europea y racional, la posibilidad preguntar a los jóvenes por lo que la política es para ellos, permite un concepto acorde a la cultura de pares que les caracteriza y a las emociones colectivas que construyen día a día. Se busca retratar un concepto que se traduzca en cotidianidades y vivencias directas a partir de las sensaciones que esta produce en los miembros de una sociedad.

Encontramos que las percepciones van entre dos polos diferenciados pero complementarios: aquellos que solo tienen palabras de crítica a la política y aquellas otras que manifiestan el necesario y vital rol de la política en nuestras vidas. De manera neutral habrá quienes se limiten a conceptuar la política sin ánimo de tomar iniciativa ofensiva o defensiva de la misma, aunque dejarán en claro la necesidad de conocer y practicar dichas ciencias. Para hablar de política, un representante del centro Federado de la Pontificia Universidad Católica del Perú, al que llamaremos «R» será cauto pues primero deberá conceptuar lo que es la política: «es el simple hecho de querer cambiar 
las cosas en el Estado o gobierno de nuestro entorno, es impulsar desde la agencia de cada uno y desde sus propias motivaciones mejoras para la sociedad $»^{2}$.

Otros representantes estudiantiles señalarán que la política se convierte en un atractivo muy grande para cierto grupo de personas que actuarán de manera egoísta desnaturalizando el concepto mismo de lo que debería ser la política. Estas opiniones vierten una rica opinión que acerca práctica política estudiantil y discurso crítico. Como parte de esta opinión S.C., representante del consejo de facultad de ciencias sociales de la Universidad Nacional Mayor de San Marcos no deja de establecer que es necesaria aunque a la larga ha sido desprestigiada: «Es una herramienta necesaria pero desprestigiada para tomar decisiones y efectuarlas desde un nivel de bases a los niveles más altos de decisión» ${ }^{3}$.

Ahora bien, otro grupo de testimonios nos acerca a la política más que como posibilidad como necesidad. Entiéndase que con necesidad se desea establecer que es una práctica que se caracteriza por ser negativa e, incluso en ciertos momentos, nefasta. Pero no se puede negar su necesaria existencia. Acaso esto se entiende en una sentencia sencilla pero significativa: «la política es frustrante, es atractiva pero no deja que se le ame completamente» ${ }^{4}$. No se puede amar aquello que dańa y que frustra las posibilidades de generar un objetivo esperado: donde hay mera contingencia y poco control puede llegar a provocar niveles de estrés emocional profundos.

Para afianzar lo establecido ahondaremos en más opiniones negativas sobre la política sin reconocer mayor aspecto positivo salvo que el de la necesidad. Una estudiante de la Universidad Nacional Federico Villarreal que apenas cursa el primer año no duda en señalar que la práctica política «está contaminada por malos políticos que buscan en primer lugar sus beneficios sin importarles que están representando al pueblo y que su labor debería dedicarse al bienestar de nuestra sociedad». Para ella la política se ve representada en autoridades y no en uno mismo, es decir tiene una perspectiva unidimensional de la política. Un estudiante de la Universidad Las Américas lanzará críticas similares: «en la política de nuestro país abunda la corrupción es por ello que no progresamos como tal ${ }^{6}$. Nuevamente se deja notar una culpa externa, ajena e impersonal. Efectivamente, los testimonios agrupados en este espacio están de acuerdo con que la culpa viene desde lo externo: «actualmente estamos mal políticamente debido a las

2 R. es hombre, tiene 19 años, vive en Pueblo Libre y estudia Sociología en la Pontificia Universidad Católica del Perú.

3 S.C. es hombre, tiene 25 años, vive en San Miguel y estudia Sociología en la Universidad Nacional Mayor de San Marcos.

4 B.B.R. es mujer, tiene 19 ańos, vive en la Victoria y estudia Sociología en la Universidad Nacional Mayor de San Marcos

5 X.N.E. es mujer, tiene 18 ańos y vive en Pachacamac. Estudia Trabajo Social en la Universidad Nacional Federico Villarreal

6 X.N. es hombre, tiene 24 años y vive en Lurín. Estudia Derecho en la Universidad Las Américas y trabaja en un restaurante. 
malas decisiones tomadas por nuestros gobernantes» ${ }^{7}$. Ni siquiera el esfuerzo de unos pocos puede salvar los objetivos finales de la política, ya que la corrupción carcome todo a su alcance: «en mayor parte tengo una visión negativa debido a la corrupción, falta de carácter y la ausencia de transparencia en la política. Aunque hay pocos que hacen bien su trabajo en su mayoría es muy torpe y decepcionante» ${ }^{8}$. La falta de carácter es la imposibilidad para castigar, expulsar y anular a quienes son la causa de los males del país, ello trae consigo poca trasparencia para saber lo que verdaderamente ocurre en dichas esferas del poder.

Si bien la mayoría de estos testimonios son negativos, hay que resaltar que ninguno de los entrevistados y entrevistadas posee un cargo político estudiantil. Se resalta ello pues es en quienes ejercen una práctica política cotidiana en donde se encuentra una reflexión que empieza por los propios ciudadanos, y más explícitamente en uno mismo. Una estudiante de la Universidad Ricardo Palma establece que la política se ha tornado en nuestra región como voluntad de caudillos populistas. Peor aún, en el Perú ello ha dado lugar a una serie de eventos negativos y frustrantes:

Es un medio por donde se difunden todo tipo de ideas ya sean de derecha, izquierda, extremistas o de centro. En América Latina, las normas políticas se han subyugado en su mayoría de veces a una persona. Sin embargo, el paso del tiempo ha hecho escoger mejor a sus dirigentes. Ahora bien, la política en el Perú, no se ha desarrollado como lo estipularon en sus inicios, es decir, un medio por el cual se resuelve los problemas de la sociedad por un parlamento que tiene una postura ideológica la cual fue aceptada por el país. En el Perú, todo se ha reducido desbarajustes en las leyes, robos, coimas, plagios, entre otros?

El Perú es el escenario de la reducción de la política y, con ella, de la esperanza y la posibilidad de mejora. Los testimonios poco a poco nos ahogarían en un nihilismo difícil de rebatir dada la construcción de sus discursos cerrados y monolíticos. C.F., estudiante de actuación nos ayuda a entender que el desinterés en la política radica en la frustración inicial que anotábamos dada la penosa práctica política en nuestro contexto: «Considero que no se mucho o casi nada de política y para mí siempre ha sido un tema del cual no me interesa saber, recién el año pasado me llamó la atención y me parece que es un tema muy mal usado en el país» ${ }^{10}$. Una estudiante de 18 años de la Universidad Ricardo Palma señala, sin mayor lugar a cambio alguno, que el Perú es un país cuya

7 E. es mujer, tiene 20 años y vive en Surco. Estudia Ingeniería Civil. Estudia en la Universidad Ricardo Palma.

8 G.R., mujer, tiene 18 años y vive en San Juan de Lurigancho. Estudia Arquitectura en la Universidad Ricardo Palma

9 M.B.P. es mujer, tiene 21 años y vive en San Juan de Lurigancho. Estudia Traducción e Interpretación en la Universidad Ricardo Palma

10 C.F. es mujer, tiene 24 años y vive en Barranco. Estudia Pedagogía Teatral en la Escuela Nacional de Arte Dramático. 
lógica de poder gira en torno a grupos de poder que se mantienen intactos a pesar de la desventura generalizada de la población: «hablar de política en el Perú es un tema muy controversial, personalmente opino que en nuestro país no puede haber un gobernador que pueda cumplir todo lo que prometa, mientras existan los grupos grandes de poder, ya que ellos hacen y deshacen a los candidatos ${ }^{11}$.

Para concluir este grupo de testimonios que critican la política sin mayor lugar a mejorarla, otra estudiante de la Universidad Federico Villarreal no duda en seńalar que la política se convierte en vehículo egoísta de beneficios individuales, enajenándose como concepto y como práctica previa: «es muy lamentable, puesto que las personas que logran obtener un cupo en la política olvidan la función que ellos tienen que cumplir, buscando así el beneficio propio olvidando a los ciudadanos del país» ${ }^{12}$. Destacamos nuevamente, al final de este acápite, que las opiniones vertidas son claras: no hay lugar a una transformación de la sociedad dado que el orden de dominación viene desde arriba. Si bien los testimonios ofrecidos no son eternos y ajenos al cambio de parecer, es destacable que casi ninguno ha incursionado en una práctica organizacional. Sin embargo, ello no desmerece, en absoluto, que su opinión refleja un sentimiento y evocan una emoción muy profunda: la tristeza y el desencanto en torno a la política. Precisamente se ha planteado, desde la academia, enfoques que toman esta perspectiva a partir de la apatía y desencanto como indicadores claramente políticos otorgándose una clara importancia a dichas emociones juveniles:

El campo político no sólo se construye en el ámbito de las urnas, sino que tiene que ver con lo que se tematiza en la vida diaria, con las posturas que los sujetos adoptan frente a aquello que los interpela. Desde esta perspectiva, resulta crucial comprender aquello que se dice y se hace en el ámbito de lo cotidiano, desde las trincheras, por ejemplo, de la apatía y el desencanto. Lo anterior desborda las fronteras formales del campo político, puesto que se enfoca en el reflujo que tiene lugar en los límites de lo público y lo privado, en una especie de esfera paralítica (González, 2012: 155)

Otros testimonios nos llevan a la necesidad de una acción política en la sociedad, a pesar de lo negativa que pueda ser. Por ejemplo un joven dirigente del partido Patria Roja deja la política en manos de quienes la ejercen ya que dependerá de ellos el modo en que se desenvuelva: "Que la política es un medio de trabajo, una forma de vida, es el arte de poder gobernar, un servicio a la comunidad, opino también que depende mucho de las personas que ejercen la política si estos hacen una buena labor entonces esta será

11 L.B. es mujer, tiene 18 ańos, viven en Lurín y estudia Ingeniería Civil en la Universidad Ricardo Palma.

12 X. N.E. es mujer, tiene 18 años y vive en Pachacamac. Estudia Trabajo Social en la Universidad Nacional Federico Villarreal 
buena en todos sus ámbitos» ${ }^{13}$. Lo resaltante aquí es la capacidad del joven dirigente por amalgamar cuatro aspectos: trabajo, forma de vida, arte y servicio. Ello nos llama a pensar la política como agencia de poderosa magnitud en aquellos quienes la ejercen, lo cual no los avasalla ni debilita dada sus ambiciones.

\section{Propuestas y opiniones para regenerar la política}

Cuando se preguntó sobre la posibilidad de regenerar la política en los entrevistados, dado que los discursos en su generalidad eran sino negativos, de completa crítica hacia un aspecto que puede ser mejorado con la participación de la población, las respuestas variaron, con sus especificidades y complejidades, en dos sentidos muy claros: aquellos que opinaban que es necesario mejores personas a cargo de toda responsabilidad política y aquellos otros que apuestan por intervenir y animar a que el resto de personas que opina negativamente tome las riendas del monstruo político. En la primera perspectiva hay comentarios diversos que nos permiten dilucidar, en definitiva, un sentimiento crítico y dispuesto a que las cosas cambien, aunque no tengan claramente cómo. Por ejemplo A.L., joven que apuesta por el cambio en su propia organización seńalará que es necesario organizarnos con miras a institucionalizar nuestras propuestas: "hace falta una mayor organización, líderes con visión de Estado mas no paternalistas, menos demagogos y sobre todo hacer partido políticos sólidos para fundar los Planes de Gobiernos con visión ideológica» ${ }^{14}$.

Otra opinión que deriva su propuesta hacia una necesaria institucionalización de la política es X.S. otro entendido en aquellos temas. Cabe destacar que, si bien es cierto al igual se aventurará hacia aspectos que definen la política clásica racional, plantea una incursión de la sociedad civil que no necesariamente se refleje en duras instituciones:

Yo creo que hay diferentes formas y una de las formas es que se fortalezcan las instituciones civiles o estatales uno de ellos los partidos políticos, por ejemplo. Pero a mí me gusta más ir por el lado de la sociedad civil, es decir a mí no me gusta del poder institucional, del poder político entendido como la política o institucionalizado si no más asociaciones civiles desde asociaciones políticas desde la misma sociedad que más bien tenga un contrapeso importante frente a partidos políticos o frente al Estado o mercado llegado el momento ${ }^{15}$.

13 X.A.P. es hombre, tiene 23 años y vive en Cercado de Lima. Estudió Ciencias Políticas en la Universidad Nacional Mayor de San Marcos. Es Presidente del Movimiento de Afirmación Social del distrito de Villa El Salvador. Es dirigente de las juventudes comunistas del Perú Patria Roja.

14 A.L. hombre de 20 ańos. Trabaja en la Municipalidad de Miraflores y estudia Gerencia de Desarrollo Humano.

15 X.S. es hombre y tiene 21 ańos. Bachiller en literatura. Trabaja como parte del staff de redactores del Perú, portal de noticias en especial de la parte política. 
Ambos comentarios nos permiten dilucidar que las juventudes organizadas en determinados ámbitos esperan cambiar la sociedad de la mano con más personas como ellos. Pero otros testimonios derivarán la responsabilidad en los demás, como bien lo dice un estudiante de medicina: "harían falta personas comprometidas con el país y honestas que no piensen en el bien propio sino en el ajeno» ${ }^{16}$. El carácter de ausencia y carencia marca la opinión del entrevistado puesto que se espera que los valores puedan cambiar el estatus quo condenado a su continua repetición. Otro testimonio refuerza este planteamiento: «una mayor educación, cultura, respeto por las demás personas una buena toma de decisiones desinteresadamente» ${ }^{17}$. La educación, amparada en buenas enseñanzas, será la única que podrá inculcar a sus ejecutores a obrar con mejores objetivos.

Más aun, el cambio pareciera estar en el futuro y no en el presente, en el mañana y no en la actualidad: «nuevas generaciones, nuevas ideas, personas de diferentes disciplinas con sentido, sensibilidad y conciencia social» ${ }^{18}$. Ello derivará en testimonios negativos y difíciles de convencer de esperanza alguna: «negatividad por delante, pues es imposible el cambio, en la medida que empiece de manera externa y no interna: No hace falta que la política se regenere, lo que hace falta es que los hombres y mujeres se regeneren, misión imposible» ${ }^{19}$. La palabra imposible se repite dos veces en quien señalaba la imposibilidad de amar la política, nos referimos a una joven estudiante de la Universidad Nacional Mayor de San Marcos para quien no hay posibilidad alguna de cambio en la medida que son los hombres y las mujeres los que causantes de ello, siendo su naturaleza imperfecta y negativa.

Otros testimonios se agruparán en aspectos muy similares: necesitamos mejores políticos. Una vez se refuerza el paradigma que insiste en un cambio externo desde arriba y no desde las propias bases. Tenemos así a un joven profesor para quien será necesario una mayor preparación profesional en quienes se animen a incursionar en la política: «Es necesario que participen en la política personas con mayor formación profesional, a fin de que tengan un mejor criterio de las decisiones a tomar ${ }^{20}$. De esta manera se refuerza una política hecha únicamente por profesionales entendidos en una materia más técnica que valorativa, aunque las críticas sean más de tipo valorativas. Una joven estudiante de Trabajo Social de la Universidad Nacional Federico Villarreal

16 X.P.J. es hombre, tiene 20 ańos y vive en el Cercado de Lima. Estudia Medicina Humana en la Universidad Nacional Mayor de San Marcos.

17 X.N.S. es mujer, tiene 21 ańos y vive en Los Olivos. Estudia Trabajo Social en la Universidad Nacional Federico Villarreal

18 X.K.T. es mujer, tiene 24 años, vive en el Cercado de Lima y trabaja como trabajadora social en Fundación Las Américas.

19 B.B.R. es mujer, tiene 19 ańos, vive en la Victoria y estudia Sociología en la Universidad Nacional Mayor de San Marcos

20 X.J.N. es hombre, tiene 25 años y vive en Chaclacayo. Estudió Gestión de proyectos en ingeniería. Es profesor universitario. 
tiene una opinión similar, se necesitan personas cuyos conocimientos estén muy por encima del común de personas: «el ingreso de personas responsables, con un grado de instrucción superior y que sepa enfrentarse a los problemas. Compromiso juvenil para afrontar la problemática política» ${ }^{21}$. Si bien concluye su opinión con la necesaria participación juvenil, pondrá en primer lugar, una vez más, aspectos técnicos y académicos, restringiendo el campo de la política a los políticos. Como establece una estudiante de una universidad privada, serán necesarios «ciertos estándares para los que ocupen los diferentes cargos existentes» ${ }^{22}$ ¿Cómo negociar entre los valores y los conocimientos?

Otro testimonio refuerza dicho planteamiento: "pienso que lo que más hace falta es cambiar a los gobernantes con pensamientos ocluidos sin miras al futuro y la falta de educación sobre política en los centros educativos para que todos podamos tener una idea más amplia de política» ${ }^{23}$. Educar políticamente a los políticos no bastará, habrá que formar a los niños en una nueva política que incluya emociones y sentimientos juveniles. Pero ello será aun mańana con las nuevas generaciones, puesto que las actuales habrían fracasado.

Por otra parte los valores serán sumamente importantes para un importante sector de jóvenes: "haría falta políticos más sinceros y que busquen un verdadero cambio, cuya motivación no sea el dinero sino el bienestar común» ${ }^{24}$. Este comentario juvenil nos lleva a pensar a los políticos como seres humanos sin mayores necesidades materiales, por el contrario tendrán un compromiso para con el resto de la sociedad, aunque ello implique perjudicarse dado su desprendimiento. Otro testimonio refuerza esta propuesta: «pienso que lo que hace falta, es un cambio en el pensamiento de los políticos, ellos buscan estar inmersos en la política por intereses económicos, mas no, por buscar soluciones a tantos problemas que aquejan al país» ${ }^{25}$. Los políticos perfectos serían aquellos que se dedicarían al entero servicio de los demás. Aunque administren la cosa pública y la economía de una nación o una localidad, no podrán ver en estos aspectos sus ambiciones personales sino colectivas. Por supuesto estas opiniones avizoran a dichos políticos de manera externa y ajena a su propia biografía. Como parte de esta opinión Una estudiante de actuación replica «la política mejoraría al tener en cuenta la verdadera realidad del ciudadano y no tanto el interés del político» ${ }^{26}$. Nuevamente habremos de centrarnos en los valores de cada persona.

21 X. N.E. es mujer, tiene 18 años y vive en Pachacamac. Estudia Trabajo Social en la Universidad Nacional Federico Villarreal

22 G.R., mujer, tiene 18 años y vive en San Juan de Lurigancho. Estudia Arquitectura en la Universidad Ricardo Palma

23 E. es mujer, tiene 20 años y vive en Surco. Estudia Ingeniería Civil en la Universidad Ricardo Palma.

24 X.E.U. es hombre, tiene 24 ańos y vive en Puente Piedra. Estudia psicología en la Universidad Nacional Federico Villarreal y toca en una banda de rock.

25 K.G. es mujer, tiene 22 ańos y vive en Surco. Estudia Arquitectura en la Universidad Ricardo Palma

26 C.F. es mujer, tiene 24 años y vive en Barranco. Estudia Pedagogía Teatral en la Escuela Nacional de Arte Dramático. 
Una estudiante de una universidad privada aunará ambos aspectos: por un lado exigirá un filtro que evite el ingreso de personas sin preparación suficiente, y por otro lado exigirá un compromiso moral de parte de aquellos que sean elegidos para tan importante tarea: «un mayor filtro para aceptar a personas a postular a cargos gubernamentales y un sincero compromiso con el desarrollo del país para que los principios de cada partido y trabajador estatal no se desintegren fugazmente» ${ }^{27}$. En esta línea podemos concluir este grupo de testimonios en que entre os valores y los conocimientos habría una predilección ligeramente mayor a la moral que debería guiar el camino del político:

Cambiar a los dirigentes y crear un partido político que refuerce los ideales en los cuales se luche por la mejora de la sociedad en todos sus ámbitos y no dejarla languidecer o vivir a costa de su esfuerzo. La política debe basarse en ayudar al bien común del ciudadano y no buscar su propio beneficio porque al final no malogra a uno sino a todos por igual ${ }^{28}$.

No creemos que ambos aspectos se separen, pero en el imaginario juvenil propuesto existiría un esfuerzo por reconciliarlos y unirlos en virtud del necesario cambio del país. Por ello es que un pequeño grupo de testimonios, para asegurar que la inmoralidad no se apropie de dicho espacio público, proponen castigar dichas acciones: una mayor rigidez podría, según sostienen, disminuir las ansias por hacerse del poder para ambiciones personales. La lógica del castigo se ejemplifica en lo que sostiene un estudiante de derecho y trabajador: «eliminar de raíz la corrupción, brindando leyes muy severas para todos los que lo incumplan ${ }^{29}$. Además de dichos aspectos negativos que corrompen tan importante práctica en beneficio de la sociedad, se avizora la impunidad como algo que la empeora y denigra, causando estragos en la ciudadanía tan negativos como dolorosos:

La política tiene un gran potencial de mejorar el bienestar de la gente que representa, sin embargo, es necesario que se extermine la impunidad ante crímenes de corrupción. Esta meta es, no obstante, bastante difícil debido a la enorme y sistemática presencia de actores posibilitadores dentro de todos los poderes estatales ${ }^{30}$.

Nuevamente se señalará lo difícil que será castigar estos actos dado que el Estado pareciera estar secuestrado por sus propios explotadores. Una joven estudiante de

27 G.V. es mujer, tiene 18 ańos y vive en San Martín de Porres. Estudia Sociología en la Universidad Nacional Mayor de San Marcos.

28 M.B.P. es mujer, tiene 21 años y vive en San Juan de Lurigancho. Estudia Traducción e Interpretación en la Universidad Ricardo Palma

29 X.N. es hombre, tiene 24 ańos y vive en Lurín. Estudia Derecho en la Universidad Las Américas y trabaja en un restaurante.

30 E. es mujer, tiene 20 años y vive en Pueblo Libre. Estudia Sociología en la Pontificia Universidad Católica del Perú 
Ingeniería Civil añade a esta crítica a los medios de comunicación por no ser imparciales y ocultar los actos de corrupción que atentan contra todos: «deberían sancionar a todo aquel político que cometa un acto de corrupción y no «tapen» los canales de televisión lo que hacen con las famosas llamadas "cortinas de humo» ${ }^{31}$. Aunando estos testimonios a los aspectos anteriores podemos dar cuenta de una política que existe en la estratosfera lejana de lo difícil, lo imposible o lo doloroso. Bajo esta mística es que se ve todo lo concerniente a la política como algo ajeno y lejano de la propia práctica cotidiana. Toda solución, por ello, puede forjarse solo desde las propias estructuras estatales, sin dar cuenta de una acción ciudadana.

Desde la perspectiva de la gubernamentalidad —en su desplazamiento conceptual que integra y enmarca la cuestión biopolítica - el Estado es el efecto de un complejo juego de estrategias que no puede ser reducido a la actuación unívoca y orgánica de un actor unitario, homogéneo y estable. Antes bien, ha de ser concebido como el resultado complejo de un proceso conflictivo en el que se diferencian, se enfrentan, se articulan, y se disputan un conjunto heterogéneo de prácticas gubernamentales (García, 2014: 65)

Creemos que estos testimonios apuestan por una crítica de lo que la administración pública ha ocasionado: nihilismo en torno a cómo deberían ser las cosas dado el modo en que vienen siendo. A continuación, un grupo de testimonios nos proponen una vía distinta: ser parte de ella para, desde adentro ser capaces de los cambios pertinentes. S.C., ex representante estudiantil en su universidad nos comenta que la ciudadanía se incorpore en estos temas dado su carácter público: «la gente tiene que entender que la actividad política es parte fundamental de nuestras vidas. La gente tiene que darse cuenta que si ellos no deciden, otros decidirán por ellos. Eso tiene que cambiar» ${ }^{32}$. La desafección política, nos menciona en joven entrevistado, no es la salida a un problema de esta envergadura, ya que los temas que aquí se tratan atańen a la «gente» de la que hace mención. Las juventudes consultadas refieren, entonces, aluden la agencia en la población como elemento vital para el cambio: «para que la política sea mejor debe haber mayor participación, cabe recalcar que la participación política no está reducida a hecho de pertenecer a una organización política ${ }^{33}$. De esta manera el término política, en boca de los jóvenes participativos, no está vedado a unos cuantos especialistas, sino a toda la población. Inclusive uno de ellos se animará a citar una frase de la filosofía griega: «Sería bueno que la gente que critica la política se inmersa en ella, como decía

31 L.B. es mujer, tiene 18 ańos, viven en Lurín y estudia Ingeniería Civil en la Universidad Ricardo Palma.

32 S.C. es hombre, tiene 25 ańos, vive en San Miguel y estudia Sociología en la Universidad Nacional Mayor de San Marcos.

33 K.U. es mujer, tiene 22 años y vive en San Juan de Lurigancho. Estudia Derecho en la Universidad Nacional Mayor de San Marcos. 
Platón el precio de no interesarse en la política es dejar que las personas mańas hagan política ${ }^{34}$.

Las juventudes requieren de la participación masiva para cambiar la sociedad, desean trascender la individualidad y hacer de lo colectivo la solución a problemas que afectan a dicho colectivo, tal como lo indica la investigación «Participación ciudadana y prácticas políticas de jóvenes en la cotidianidad», la política se torna algo cotidiano, una lucha diaria que es la que caracterizara la propia vida: «son conscientes de que marcan una diferencia respecto a los demás jóvenes, razón por la cual hay una crítica muy fuerte ante la pasividad y el conformismo de sus pares, porque sienten que están llamados a ejercer un papel protagónico en el cambio de la sociedad y confían en que pueden hacerlo» (Agudelo-Ramírez, Murillo-Saá, Echeverry-Restrepo, Patiño-López, 2010: 598)

Dichos jóvenes se sienten distintos y por ello acuñan un compromiso con sus respectivas organizaciones. R. joven representante del centro federado en la Pontificia Universidad Católica del Perú nos convence de la necesidad de reconciliarnos con nuestros prejuicios y sentimientos de rechazo:

Para poder volver a confiar en la política y que lo volvamos a pensar como un espacio donde podemos realizar mejoras y no como un espacio para enriquecernos, es necesario que cambiemos y demostremos que es posible repensar la política de una manera positiva, y la única manera de lograr esto es involucrándose ${ }^{35}$.

Las juventudes entrevistadas abrigan esperanzas incluso allí donde no niegan que es sumamente difícil el cambio dado el contexto sistemático al cual se enfrentan como meros individuos de buena voluntad. No niegan la dificultad atribuida líneas atrás, la toman como un reto de múltiple importancia. T., joven estudiante de Sociología, nos lo deja muy claro en una amplia, clara y emotiva opinión:

Creo que lo que hace falta es que sea más atractiva para la gente. Si tú eres nuevo y entras al espacio político, lo más común es que, si no eres un megalómano con ansias de poder o te alías con alguien parecido, sufras mucho, veas tus iniciativas ignoradas, atacadas. Te veas a ti mismo atacado o criticado por ser como eres. Por lo tanto no hay ningún incentivo para que quieras quedarte, a menos que tengas una voluntad de hierro. Es necesario empezar a mostrarla como un espacio en donde se pueden

34 X.A.P. es hombre, tiene 23 años y vive en Cercado de Lima. Estudió Ciencias Políticas en la Universidad Nacional Mayor de San Marcos. Es presidente del Movimiento de Afirmación Social del distrito de Villa El Salvador. Es dirigente de las juventudes comunistas del Perú Patria Roja.

35 R. es hombre, tiene 19 años, vive en Pueblo Libre y estudia Sociología en la Pontificia Universidad Católica del Perú. 
hacer cosas, en donde uno puede aprender, en donde ser nuevo o diferente no es un impedimento para hacer cosas. Solo con gente así podremos hacerle frente a los que clásicamente han tenido el manejo de estos espacios ${ }^{36}$.

El sufrimiento y el dolor menguan las posibilidades de una agencia transformadora debido a los peligros a los que uno se enfrente. La joven estudiante universitaria sabe muy bien que no hay nada que te aferre a intentar hacer mejor las cosas, sin embargo la fortaleza da lugar a la efervescencia colectiva del «nosotros», uno a uno podrá sumar esfuerzos y convertir la fragmentación indecisa en una voluntad común de «hierro». En la investigación «Jóvenes y política: de la participación formal a la movilización informal» (Arias-Cardona y Alvarado, 2015) sus autores plantean el modo en que la resistencia juvenil tiene lugar mediante estrategias innovadoras para hacer frente a los problemas clásicos de la política. Cada ímpetu individual se va multiplicando re creando mayores redes de esperanza, lo cual, a decir de los investigadores, supone:

[...] Agenciar procesos individuales y colectivos de resistencia ante lo dominante, lo violento o lo injusto, a través de creaciones estéticas y políticas que dan cuenta de la lucha donde se tejen nuevas solidaridades, anhelos y utopías alternativas al orden imperante que configuran nuevas formas de construcción de lo público y de las relaciones de poder. Así, al hablar de los jóvenes y las jóvenes se puede hablar entonces de sujetos políticos activos en la construcción de sus biografías e historias colectivas, que reconocen la diferencia y transforman conscientemente las condiciones -políticas, sociales, económicas y culturales- relacionadas con el ejercicio ciudadano. (AriasCardona y Alvarado, 2015: 589)

Otra estudiante de sociología, esta vez de una universidad estatal, comparte las opiniones anteriormente vertidas estableciendo, agregando, además, que este hecho recrudecerá en una suerte de estructuración egoísta y patrimonialista. Su explicación de corte causalista intenta aproximarse a la apatía generalizada que provoca la acusada complementariedad entre entre el desinterés y el aprovechamiento de otros:

Haría falta más conciencia en las personas que participan activamente haciendo política, demostrarle a la población que sí se puede dar un cambio y en realidad se necesita mejores personas, solo eso porque esta tan manchada la palabra política que todo aquel que entra ya de por si piensa en sacar beneficio de esto y es una cadena que en algún momento debemos de parar, decir hasta aquí porque no es posible que toda esta gente tenga comportamientos tan negativos, es como que todos fueran sacados del mismo

36 T. es mujer, tiene 21 años y vive en La Molina. Estudia Sociología en la Pontificia Universidad Católica del Perú 
agujero y la población sufre una decepción es por ello que en su mayoría no asumen un papel participativo y así es un ciclo que está ahíi ${ }^{37}$.

Los testimonios ofrecidos que convergen en una necesaria participación colectiva nos obligan a una aproximación hacia las juventudes organizadas que, aunque no sean una gran mayoría, están de acuerdo con que el cambio irá desde las raíces. Agudelo-Ramírez, Murillo-Saá, Echeverry-Restrepo, Patiño-López (2010, p. 595) explican que dicho sector de la población «valora cada práctica como un paso para lograr transformaciones sociales, aunque reconozcan que ciertas acciones no generen grandes impactos o no lo hagan en el plazo inmediato». Para los autores las juventudes aludidas en Latinoamérica poseen un enorme ímpetu que los lleva a confiar en que cada persona puede ser parte del cambio, sin caer en ilusiones infundadas ya que «tienen claro que una sola persona no hace el cambio, pero que este germina en la conciencia cada quien» (Agudelo-Ramírez et. al., 2010, p. 595). De esta manera puede notarse el modo en que las formas de ser y estar de las juventudes "parecen tener unos modos de expresión que giran en torno a la adscripción-integración, la resistencia -crítica y la reclusión - evitación» (López, 2011, p. 17). Tales aspectos antes que rechazarse, se complementan en un deseo común, hacer de la política algo muy diferente.

\section{Compromiso juvenil para afrontar la problemática política}

En esta última parte del informe daremos cuenta del compromiso de la juventud para poder ser parte de la solución al problema. Para ello se les preguntó aquello que pueden hacer desde sus propias acciones para agenciar o intentar agenciar algún cambio. En efecto, el compromiso de distintos jóvenes organizados será de transformar la política desde una perspectiva que implique cambiar el modo de pensar de la población dado que los prejuicios los divorcian de todo tipo de deliberación y opinión en torno a intereses públicos y legítimamente colectivos. J.P., una estudiante de Sociología de una universidad estatal, lo dice así: Para mejorar la politica lo primero que se tendria que hacer es contrarrestar el apolitismo, pues el hacer politica está visto como algo que no se debe de hacer, o en algunos casos politica es sinónimo de corrupción lo cual no escapa de la realidad ${ }^{38}$.

S.C. por su parte no deja de retratar la política en su propia vida puesto que se identifica con su práctica, tal como él lo percibe. Propondrá algo menos universal y más particular: Una politica a escala micro en un espacio donde lamentablemente todos los espacios de decisión (administrativos, logisticos y académicos) se resuelven en el campo

37 F.M.A. es mujer, tiene 19 años y estudia Sociología en la Universidad Nacional Mayor de San Marcos.

38 J.P. es mujer, tiene 20 años y vive en San Juan de Lurigancho. Estudia Sociología en la Universidad Nacional Mayor de San Marcos. 
político $^{39}$. Este vínculo cotidiano y, a la vez, estructurante de la política más general, reflejará su propia manera de hacer política a través de su propia cotidianidad organizativa. Existirán otros casos en que los jóvenes participativos sentirán la atracción como resultado de un proceso educativo ligado a entornos más cercanos. Ello termina por animarlos a proponer estrategias de mejora colectiva, sintiendo que su actuar trasciende cualquier decisión personal. T. un estudiante de sociología de la universidad privada nos relata en su biografía la manera en que sería marcado: Mi tío Teodoro me decía que la trascendencia consistia en hacer algo importante para tu sociedad. Y eso no era otra cosa que hacer politica. A los 17 años fui a un taller del partido Tierra y Libertad y me enamoré de lo que hacian. ${ }^{40} \mathrm{~T}$. tuvo la posibilidad de ver muy de cerca qué era la política partidaria, con lo cual definiría buena parte de su juventud hasta el día de hoy.

El caso de otra joven es muy importante puesto que a través de su experiencia en la toma del espacio urbano a partir de una protesta de suma importancia en el Perú: la marcha contra el régimen laboral juvenil en el año 2014. A partir de aquel momento sintió que la política aunaba a cada miembro de un modo colectivo:

La «marcha contra el nuevo régimen laboral juvenil» fue la primera a la que asistí. Ya había asistido a unas anteriores, pero dentro de la universidad. Fue una experiencia bastante grata, sentí que era parte de algo grande, sentí que las personas se habían cansado y estaban en las calles para reclamar sus derechos, sentí que podíamos cambiar las cosas...me sentí muy bien ${ }^{41}$.

La lucha contra la injusticia en aquella marcha representaba una lucha abierta contra el adultocentrismo, es decir contra la maquinaria que organizaba la sociedad exlucyendo a las juventudes como meros receptores. A decir de Vásquez (2010) esta visión patriarcal negaría el reconocimiento de manifestaciones juveniles distintitas para vivir y experimentar la vida, además de que «las deslegitima con el propósito de evitar las emergentes expresiones contra hegemónicas» (Vásquez, 2010: 48). Para este investigador, heredero de las fuentes foucaulteanas del biopoder, el adultocentrismo impulsa una "correcta» manera de ver el mundo e insertarse en él. Esta inserción obliga a acatar la lógica del mercado del consumo y de producción para luego culpar a las juventudes de una «fiebre consumista». A la larga:

La máquina adultocéntrica produce sujetos consumistas y luego utiliza este calificativo para desacreditar a los sujetos que ha creado. El consumismo es uno más de los

39 S.C. es hombre, tiene 25 años, vive en San Miguel y estudia Sociología en la Universidad Nacional Mayor de San Marcos.

40 T. es hombre, tiene 21 años, vive en Jesús María y estudia Sociología en la Pontificia Universidad Católica del Perú

41 K.U. es mujer, tiene 22 ańos y vive en San Juan de Lurigancho. Estudia Derecho en la Universidad Nacional Mayor de San Marcos. 
malestares que, en los discursos de carga moral, se atribuye a los jóvenes de este tiempo, a la vez que constituye la estrategia de la que se vale la misma máquina que las genera (Vásquez, 2010, p.48)

El caso de un estudiante de la Pontificia Universidad Católica del Perú, refleja, en efecto, el modo en que esta marcha no solo generó el reflejo de un descontento, sino la «semilla» de un ejercicio ciudadano que vincula al individuo con un compromiso político lejos del desencanto y la apatía:

Yo fui, bajamos, nos juntamos con gente de la PUCP, marchamos con la gente de la PUCP, la verdad es que me pareció una marcha súper pacifica, hasta creo que por Ancash, por Abancay, nos tiraron lacrimógenas, me confundí. Si yo siento que hubo una semilla, siento que hay esperanza, y eso es lo más importante, el problema es como analizas eso, yo creo que hay varias cosas que se pueden copiar o imitar, y creo que «podemos» es una buena praxis política. ${ }^{42}$

De esta manera nos damos cuenta de la importancia que cobra analizar la protesta juvenil a partir de la «idea de la centralidad de un Estado desplazado» (García, 2014, p. 66), es decir comprendiendo el rol que el Estado posee como «espacio crucial en la disputa con las prácticas y los efectos de poder de las tecnologías gubernamentales que imponen o quisieran imponer las lógicas del mercado (García, 2014, p. 66). Asimismo las participaciones en las marchas y protestas podrán ser producto de la integración de sus miembros sin que necesariamente haya un conocimiento profundo de los objetivos más lógicos o las valoraciones éticas de aquellas. Para un estudiante de la Pontificia Universidad Católica del Perú, sería mejor ser consciente de lo que se hace y por qué se hace:

Prefiero una participación consciente, alguien que se ha informado previamente y que tenga una idea clara del porque esta persona participa y que el amigo le haya pasado la voz y le haga la taba. De hecho, que sí pero también es como en temas de hechos públicos por temas de violencia por parte de estado porque las agresiones siempre han existido siempre, ahora se han visto casos de corrupción, pero igual te arrojan bombas lacrimógenas al cuerpo, y eso como que uno debe estar preparado siempre un poco de vinagre nunca esta demás. Pero no necesariamente tienes que saber, ¡si es que nadie te dice $!^{43}$

42 X.S.S. es hombre de 22 años y estudia Ciencias Políticas de la Pontificia Universidad Católica del Perú.

43 X.Y. es hombre de 21 años y estudia Ciencias de la Comunicación de la Pontificia Universidad Católica del Perú. 
Tal como establecen Botero, Vega y Orozco (2012) lo político está en constate movimiento dado que tanto movimientos como colectivos intergeneracionales recrean la propia educación mediante sus prácticas y discursos. Dichos autores plantean:

Es importante reconocer que dichos marcos permiten comprender que los procesos de socialización política van más allá del lenguaje y de la consciencia, y si bien se diferencian los procesos de socialización en momentos como la socialización primaria y secundaria, las experiencias expuestas posibilitan sustentar las relaciones afectivas, culturales y contextuales que impregnan sentidos en los procesos de formación de sus miembros. Frente a esta diferenciación, los jóvenes y las jóvenes posibilitan ampliar la noción de formación política en los tejidos de relaciones intergeneracionales, a partir de las dimensiones que implican sus narraciones histórica, identitaria e intercultural; autoformación y co-creación como procesos de socialización al interior de cada experiencia. Estas experiencias convocan a los procesos de socialización más proximales y afectivos, que median prácticas, acciones y resistencias hechas cuerpo, capaces de desobediencia civil, aptos para poner en duda los lugares comunes de los sucesos contextuales, políticos y culturales en la región (Botero, Vega y Orozco, 2012, p. 909)

\section{Conclusiones}

Se ha partido de una noción de la política menos exclusiva y más extensa, así como de una perspectiva más cultural que únicamente de dominación. A partir de ello y de la mano de un estado de la cuestión que nos remiten a un análisis más comprensivo que sea capaz de aunar las diferentes y múltiples miradas juveniles sobre la política, se ha planteado una exploración de lo que la política representa para las juventudes universitarias. En este contexto se ha elegido tanto a jóvenes comprometidos organizacionalmente con el cambio colectivo y otros jóvenes dedicados a sus estudios y a su propia cotidianidad. A partir de ello es que podemos acercarnos a diversas conclusiones, entre las cuales destacaremos las siguientes:

No puede hablarse de polaridad entre la apatía y el compromiso político juvenil. Ambas perspectivas parten de una crítica hacia la manera tradicional de hacer política, por lo cual antes que separarse deben integrarse para resultados más complejos y productivos que deseen estudiar el fenómeno juvenil participativo.

Las juventudes organizadas entrevistadas se sienten llamadas al cambio y a la transformación, partiendo siempre de una posición muy intersubjetiva, llamando a la colectividad a formar parte de un cambio masivo. No se pueden percibir lejos de la cosa pública, sino muy insertos en dinámicas políticas críticas que busquen un mayor beneficio para la sociedad. 
Las juventudes no organizadas que perciben la política como algo negativo o muy difícil de cambiar, apuestan por una perspectiva alejada de la tradicional, negándola en todo momento, proponiendo una mejor preparación moral y profesional. Sin embargo, no se ven insertos en dicho cambio y tecnificarán la política en manos de unos cuantos elegidos antes que una política que parte de sus propias manos. Ello nos lleva a la necesidad de profundizar aún más el modo en que dichas juventudes vislumbran el cambio.

Se aprecia una relación en tres aspectos muy claros y definidos: uno primero en torno a jóvenes entre los 18 y 20 ańos que desean un cambio a partir de mejor preparación, valores y rigidez normativa; un segundo ámbito de jóvenes entre 20 y 25 años que plantean cambios diferentes a los tradicionales a partir de cotidianidades comunes y sencillas sin que sean únicamente institucionales. Un tercer y último ámbito pertenece a jóvenes comprometidos o bien en partidos políticos o bien como profesionales del tema, que vislumbran el ejercicio político mayormente de manera institucionalizada.

Los tres aspectos antes que una mera clasificación responden a necesidades distintas: jóvenes que empiezan a vincularse con dinámicas organizativas universitarias; jóvenes comprometidos con cambios y dispuestos a proponer dinámicas menos rígidas y más integradoras y jóvenes que apuestan por la carrera política institucional, que, si bien radican en la tradición política dicotómica del estado frente a la sociedad civil, se caracterizarán por poseer un ímpetu muy importante a resaltar, dado de que se encuentran convencidos del cambio que pueden propiciar.

Existe una economía de las emociones y sentimientos que lleva a las juventudes a evitar el tema político para soslayar el sufrimiento que representa el engaño y la traición que implica la política tradicional. La misma economía se puede notar en quienes han decidido ser parte de prácticas políticas menos verticales y más horizontales, con la diferencia de que deciden enfrentar dichos sentimientos fortalecidos por una esperanza colectiva, organizada y potenciada por otros como ellos y ellas. Se sienten acompańados y cada paso que darán será un paso plural.

La investigación planteada dilucida un necesario acercamiento de voluntades y de emociones intersubjetivas para entender la política en el discurso y en la cotidianidad. Se propone renovar los enfoques clásicos, incorporando el cuerpo y las emociones en el análisis de lo que la política es y lo que puede llegar a ser (y que viene siendo) en la práctica común y corriente de muchos jóvenes en sus correspondientes espacios a pequeña, pero muy fortalecida, escala. 


\section{Referencias}

Adrianzén, A. (2010) El regreso del Estado. En El Estado en debate: múltiples miradas. Lima: PNUD.

Agudelo-Ramírez, A., Murillo-SaÁ, L., Echeverry-Restrepo, L. \& Patiño-López, J. A. (2013). Participación ciudadana y prácticas políticas de jóvenes en la cotidianidad. En Revista Latinoamericana de Ciencias Sociales, Niñez y Juventud, 11 (2), pp. 587-602.

Aguilera, O. (2012) Repertorios y ciclos de movilización juvenil en Chile (2000-2012). En Utopia y praxis latinoamericana $\mathrm{N}^{\circ}$ 57. P.101-108.

Araya-Castillo, L. y Etchebarne, S. (2014). Personalidad de marca de partidos Políticos: Una mirada desde la comunidad estudiantil universitaria. En Revista Latinoamericana de Ciencias Sociales, Niñez y Juventud, 12 (1), pp. 225-241.

Arias-Cardona, A. M. \& Alvarado, S. V. (2015). Jóvenes y política: de la participación formal a la movilización informal. En Revista Latinoamericana de Ciencias Sociales, Niñez y Juventud, 13 (2), pp. 581-594.

Castells, M. (2012) Redes de indignación y esperanzas. Madrid: Alianza Editorial.

Castells, M. (2009). Comunicación y poder. Madrid: Alianza Editorial.

Carena, S., Pisano, M. y Tessio, A. (2009) Ser joven en América Latina a comienzos del tercer milenio. En Diálogos pedagógicos No 13. Pp. 13-33.

Dussel, E. (2006) 20 tesis de política. México D.F.: Siglo XXI.

Fernández, E. (2015) La rebelión de los pulpines. Lima: Otra mirada.

García, H. (2014) El Estado según Foucault: soberanía, biopolítica y gubernamentalidad (2000-2012). En Utopía y praxis latinoamericana $\mathrm{N}^{\circ}$ 57. P.53-66.

GonZÁLEZ, J. I. I. (2012). (De)construyendo la esfera pública. Juventud y (la otra) cultura política. En Revista Latinoamericana de Ciencias Sociales, Niñez y Juventud, 10 (1), pp. 147-157.

Klein, O. (2012) El movimiento de los indignados. En El Cotidiano No 173. Pp.89-98.

LeChner, N. (2002) Las sombras del mañana. La dimensión subjetiva de la política. Santiago de Chile: LQM Ediciones.

LoAYZA, J. (2013a) Avances teóricos en torno a una epistemología del cuerpo, las emociones y lo político. En Revista Austral de Ciencias Sociales. No 24. Pp. 51-69.

Loayza, J. (2013b) ¿Qué dicen los y las jóvenes acerca de la política? Acerca de los discursos en referencia a la política. En, Roberto Rodríguez (ed.) Movimientos juveniles en América Latina y El Caribe. Pp. 217-231.

López, M. (2011) Producción y expresión de la subjetividad en la juventud contemporánea. En Revista de la Facultad de Trabajo Social UPB N ${ }^{\circ}$ 27. Pp. 12-21.

Piñeyro, C. (2013) La otra democracia: la autonomía como alternativa política en América Latina. En Utopia y praxis latinoamericana $\mathrm{N}^{\circ}$ 63. P.33-48.

Roitman, M. (2012) Los indignados. El rescate de la política. Madrid: AKAL. 
Secretaría Nacional de la Juventud - SenAJU (2015) Población juvenil en el Perú, cifras regionales 2015. Lima: Autor. Disponible en http://juventud.gob.pe/media/publications/ poblacion-juvenil-en-el-peru.pdf

VÁsquez, J. (2010) Subjetividades juveniles y discurso del éxito. Entre la emancipación y la institucionalización de las prácticas. En Anuario Electrónico de Estudios en Comunicación Social Disertaciones N³ Disponible en http://erevistas.saber.ula.ve/index.php/Disertaciones/ 